\title{
A systematic review of burnout and its relation to work-life balance and scheduling among United States physicians
}

\author{
Evan Reinhart DO, Kelsey Reely MD, Kristen Dowdy DO, Nikhil Seth MD, Patrick McGrade MD, \\ Clinton Jones DO, M. Jensen Horan BS, Noelle Provenzano BS, Patrick Ramirez MD, \\ Kendall Hammonds MS, Shamyal Khan DO
}

\begin{abstract}
Physician burnout has been recognized as a multifactorial issue leading to detrimental outcomes for both the individual physician and patients being treated. Burnout is defined as "a pathological syndrome in which emotional depletion and maladaptive detachment develop in response to prolonged occupational stress." It has been proven that poor work-life balance, a state in which personal life and professional life are in a state of imbalance, is directly connected to burnout. Upward of $61 \%$ of all United States physicians are dissatisfied with their worklife balance (WLB). Burnout rates among physicians are positively correlated with frequency of work-home conflicts leading to greater dissatisfaction of their WLB. With the prevalence of burnout among US physicians ranging between 34-76\%, addressing modifiable causes such as optimizing WLB should be a priority for administrators and residency directors. In this systematic review, we explore the importance of creating a schedule that prioritizes protecting a physician's WLB as a means to decrease burnout and the associated sequelae, including medical errors, alcohol and drug abuse, and depression. After identifying 202 studies through a PubMed keyword search and screening for specific criteria, data from 21 articles published between 2011-2018 were included and analyzed. We found that schedules that emphasize the following parameters were protective of physician WLB and burnout: $<70$-hour work week goals, a maximum of one on-call night per five consecutive days, providing physicians with schedule information a minimum of one month in advance, limiting the number of consecutive work days to five, and providing allotted vacation time. As the importance of mental health and wellness within the health care setting are being regarded as a cause of concern, it is apparent that positive changes need to be made.
\end{abstract}

Keywords: Physician, work-life balance, burnout, schedule

\section{INTRODUCTION}

Physician burnout is a complication of practicing medicine. The prevalence of burnout may range anywhere between $34-76 \%{ }^{1-7}$ and is especially pervasive among young physicians who are dissatisfied with

Corresponding author: Patrick McGrade Contact Information: Patrick.mcgrade@bswhealth.org DOI: 10.12746/swrccc.v8i34.663 their Work-Life Balance (WLB). ${ }^{1,8-11}$ Hospital administrators and residency directors should be keen to minimize burnout among their practitioners to avoid the associated sequelae. The implications of these side effects carry not only potential financial burdens to the hospital but are profoundly devastating to the individual practitioners and their families. ${ }^{3}$

The list of potential detrimental effects on society caused by burnout is extensive, and the need for intervention is becoming more apparent. One Mayo 
Clinic study used standardized burnout and satisfaction scores within its community and found that as physicians' burnout scores increased, their work hours and productivity decreased. This invariably led to decreased access to care for patients as each practitioner in the burnout category had fewer work hours, performed fewer surgeries, and reduced their full time work hour equivalents. $^{12}$

There is also substantial evidence that links physician burnout with physician depression, and behavioral impairment is a recognized risk factor for medical errors. A 2016 survey found that depressed pediatric residents were $>6$ times more likely than the nondepressed residents to make medical errors, causing distress to patients and families and increasing hospitals costs due to ordering unnecessary tests and incidental patient harm. ${ }^{13} \mathrm{~A}$ national study of 8,000 U.S. surgeons noted that $9 \%$ admitted making a medical error during the three months of the study with a positive relationship between burnout scores and errors. ${ }^{14}$ Another study reported that oncologists characterized as "burned-out" were linked to personal repercussions that included breaking off personal relationships, alcohol abuse/dependency, and suicide risk. ${ }^{15}$

The causes of burnout among U.S. physicians are certainly multifactorial; however, it often can be attributed to one of two central reasons: First, the inherent stress of practicing medicine and second, the demanding and tedious schedules required to remain a current and safe practitioner. In this study, we aimed to evaluate the latter, noting that, while the nature of medicine hinders the ability to create ideal scheduling parameters, certain elements can be correlated with WLB satisfaction and should be addressed when possible. ${ }^{16}$

In this literature review, we highlight which elements of physicians' schedules increase WLB satisfaction and, therefore, may serve as a means to decrease burnout.

\section{METHODS}

A PubMed electronic search was completed using the search terms physician, schedule, burnout, and work-life balance (Figure 1). Two hundred two unique article titles and abstracts were identified and screened

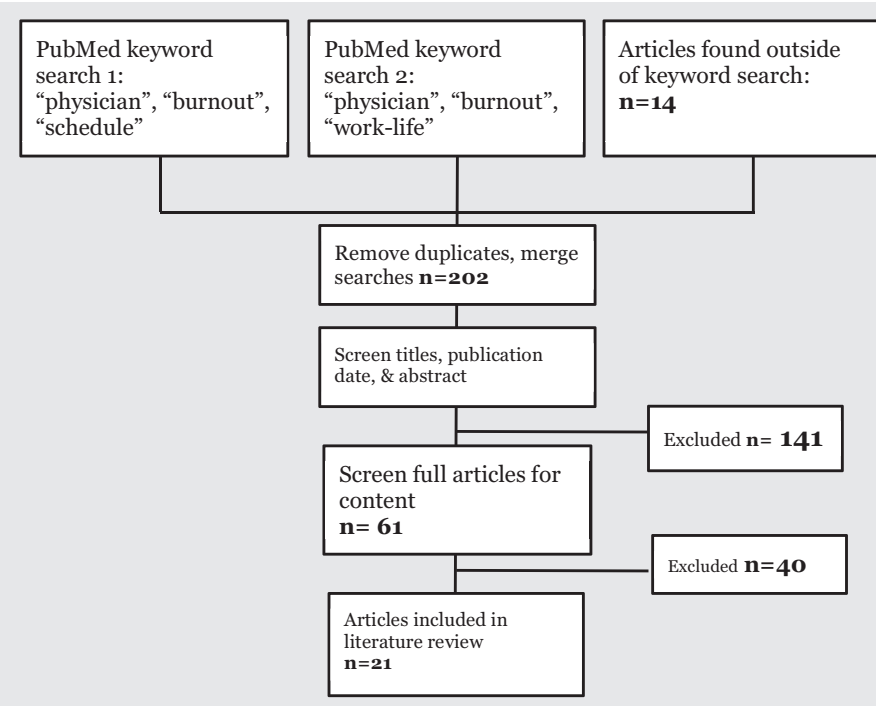

Figure 1. Literature search strategy.

using predetermined inclusion and exclusion criteria (Figure 2). Sixty-one full articles were identified and screened. The search query included all available articles up to October 2017. The inclusion criteria used focused on data published between January 1 , 2011, and October 1, 2017, U.S. physicians and their partners, evaluation of contributing factors of burnout, work-life balance, work-home conflicts, and/or quality of life. Exclusion criteria were articles not based on U.S physicians. All statistical analysis was performed in SAS 9.4. Aggregate odds ratios and confidence intervals were calculated using the inverse variance method. Statistical significance was set to $<0.05$.

1. Publish date between January 1, 2011 and October 1, 2017

2. United States physicians or partners of United States physicians

3. Evaluates contributing factors of burnout, work-life balance, work-home conflicts, and/or quality of life

4. Full manuscript available in English

Figure 2. Inclusion criteria. 


\section{RESULTS}

A total of 21 articles met inclusion criteria. ${ }^{1-11,13,17-25}$ A complete list of the articles and their key characteristics are summarized in Table 1. Eighteen of these articles included data from cross-sectional, retrospective studies, ${ }^{1-5,7-11,17-25}$ one study was a randomized, multicenter trial, ${ }^{7}$ and two had cross-sectional, longitudinal designs. ${ }^{2,13}$ Eighteen studies collected data from physicians ${ }^{1-6,8-11,13,17-22}$ and three from spouses/ significant others of physicians. ${ }^{15,23,25} \mathrm{~A}$ variety of validated and non-validated measurement tools were used for data collection and analysis. The 2-item or full Masloch Burnout Index were the two most common methods to identify burnout and were used in 14 of the articles. ${ }^{1,3-5,8-12,14-17,20-23,25}$ We found schedules that emphasize the following parameters improved physician WLB and reduced work-home conflict and burnout: $<70$ hour work week goals, ${ }^{3,5}$ a maximum of one on-call night per five consecutive days, ${ }^{1,3,4,5,9-11,22,23}$ providing physicians with schedule information a minimum of one month in advance, ${ }^{2,13}$ limiting the number of consecutive work days to five, ${ }^{3}$ and providing allotted vacation time. ${ }^{21}$ The current literature on physician schedules reported a correlation between workhome conflicts and the risk of physicians' experiencing burnout. ${ }^{1,10}$ The studies reported that physicians who experience difficulties in their home lives were more susceptible to have the negative outcomes associated with physician burnout.

Although the reported hour ceiling of 70 hours produced an odds ratio suggesting burnout protection, it was determined that working greater than 60 hours ${ }^{10}$ increased the likelihood of work-home conflict. On further evaluation, the reviewed manuscripts, while not specific to a particular specialty, produced the following odds ratios: Working $>70 \mathrm{~h} / \mathrm{wk}$ positively correlated with burnout: 2.50 (2.15-2.91); Each additional hour of work per week correlated with burnout: 1.02 (1.011.02); Each additional night on call, burnout: 1.05 (1.03-1.06); More than one night on call per week, emotional exhaustion: 1.96 (1.29-2.97); More than two nights on call per week, burnout: 1.95 (1.58-2.4); 5 days or more in between nights on call, burnout: 0.62 (0.45-0.86); > 50 work hours per week, satisfaction with WLB: 0.21 (0.13-0.33); >60 work hours per week, likelihood of work-home conflict: 2.27 (2.03-2.54); Recent work-home conflict, burnout: 2.46 (2.20-2.75); $2+$ nights on call per week, likelihood of work-home conflict: 1.32 (1.18-1.46); Takes vacations, burnout: 0.86 (0.75-0.98); Known schedule at least one month in advance, job satisfaction: 3.6 (1.91-6.79); (as referenced in Table 2).

\section{Discussion}

Upward of $61 \%$ of all US physicians are dissatisfied with their WLB..$^{8,16-19}$ Burnout rates among physicians are positively correlated with frequency of work-home conflicts and dissatisfaction of WLB..$^{1,8-11}$ Many young practitioners beginning their medical careers have experienced burnout at alarming rates. The prevention of depression, alcoholism, and ultimately medical errors should remain a mutual interest of providers and their employers and hospitals. Physicians experiencing burnout are twice as likely to be involved with patient safety incidents, twice as likely to provide suboptimal care to patients, and three times more likely to receive low patient satisfaction scores. The financial burden acquired through during training has increased over the past decade, and protective measures if available should be implemented to preserve physicians' mental health. Previous meta-analyses have shown the correlation between patient outcomes and physician burnout, and there have not been clear scheduling recommendations to prevent burnout and/ or protect physicians' mental health. ${ }^{26}$

We present suggestions to help reduce the rising incidence of physician burnout within medicine's current culture. Based on our findings, an ideal schedule could be best implemented within group practices with 5 or more physicians in most specialties. This would include work schedules being made at least one month in advance. Each physician could rotate call allowing for optimal rest time in between. On weekend call, some physicians could remove a day of work, e.g., take Friday off in substitution for a call Saturday, leading to a $<70$-hour work week. Vacation time can be approved with $>1$-month notice to allow providers to adapt their schedules as needed. While this review provides for some broad starting points for administrators to use in their own departments, there are limitations to this 
Table 1. Characteristics of Studies Included in Review

\begin{tabular}{|c|c|c|c|c|c|c|c|}
\hline Source & Design & Population & $\begin{array}{l}\text { Training } \\
\text { Level }\end{array}$ & Number & $\begin{array}{l}\text { Response } \\
\text { Rate }\end{array}$ & $\begin{array}{c}\text { Mean } \\
\text { Age }\end{array}$ & $\begin{array}{l}\text { Burnout, QOL, etc } \\
\text { measurement tools }\end{array}$ \\
\hline Ali, $2011^{6}$ & $\begin{array}{l}\text { Cohort } \\
\text { study, } \\
\text { RCT } \\
\end{array}$ & Intensivists & Attending & 39 & $87 \%$ & 41 & $\mathrm{NV}$ \\
\hline de Oliveira, $2013^{5}$ & $\mathrm{CS}$ & Anesthesiologists & Residents & 1508 & $54 \%$ & - & $\begin{array}{l}12 \text { question MBI-HSS, } \\
\text { HANDS, scales for errors }\end{array}$ \\
\hline Dyrbye, $2012^{2}$ & $\mathrm{CS}$ & Surgeons & All levels & 7197 & $28.7 \%$ & - & $\begin{array}{l}\text { 2-item MBI, 2-item } \\
\text { PRIME-MD }\end{array}$ \\
\hline Dyrbye, $2011^{1}$ & $\mathrm{CS}$ & Surgeons & All levels & 7858 & $31.5 \%$ & 51 & $\begin{array}{l}\text { MBI, 2-item PRIME-MD, } \\
\text { SF-12 }\end{array}$ \\
\hline Dyrbye, $2013^{7}$ & $\mathrm{CS}$ & Physician partners & None & 891 & $54 \%$ & - & $\begin{array}{l}\text { 2-item MBI, QOL } \\
\text { LASAs, PRIME-MD }\end{array}$ \\
\hline Dyrbye, $2013^{8}$ & $\mathrm{CS}$ & All specialties & All levels & 7288 & $26.3 \%$ & - & MBI \\
\hline Dyrbye, $2011^{9}$ & $\mathrm{CS}$ & $\begin{array}{l}\text { Physician Faculty, } \\
\text { internists }\end{array}$ & Attending & 465 & $82.2 \%$ & - & 2-item MBI \\
\hline Guest, $2011^{11}$ & $\mathrm{CS}$ & $\begin{array}{l}\text { Faculty, surgical } \\
\text { oncologists }\end{array}$ & Attending & 72 & $73 \%$ & - & $\begin{array}{l}\text { MBI-HSS, LASA QOL, } \\
\text { AUDIT }\end{array}$ \\
\hline Holmes, $2017^{4}$ & $\mathrm{CS}$ & All specialties & Residents & 307 & $61 \%$ & - & MBI, PHQ-9 \\
\hline Qureshi, $2015^{3}$ & $\mathrm{CS}$ & Plastic Surgeons & Attending & 1691 & $28.5 \%$ & 51 & $\begin{array}{l}\text { MBI, SF-8, PRIME-MD, } \\
\text { AUDIT }\end{array}$ \\
\hline Rabatin, $2016^{2}$ & CS \& L & $\begin{array}{l}\text { Family physician, } \\
\text { general internists }\end{array}$ & Attending & 422 & $56.0 \%$ & - & NV \\
\hline Roberston, $2017^{19}$ & $\mathrm{CS}$ & Primary care & $\begin{array}{l}\text { Residents, } \\
\text { teaching } \\
\text { physicians }\end{array}$ & 585 & $68 \%$ & - & $\mathrm{NV}$ \\
\hline Sargent, $2012^{25}$ & CS & Physician partners & None & 428 & - & - & MBI, GHQ-12, RDAS \\
\hline Shanafelt, $2014^{17}$ & $\mathrm{CS}$ & Oncologists & Fellows & 1,373 & $83.9 \%$ & 33 & 2-item MBI \\
\hline Shanafelt, $2013^{23}$ & $\mathrm{CS}$ & Physician partners & None & 891 & $54.2 \%$ & 51 & NV \\
\hline Shanafelt, $2012^{21}$ & $\mathrm{CS}$ & Surgeons & All levels & 7197 & $28.7 \%$ & 53 & $\begin{array}{l}\text { 2-item MBI, QOL } \\
\text { LASA }\end{array}$ \\
\hline Shanafelt, $2012^{20}$ & $\mathrm{CS}$ & All specialties & All levels & 7288 & $26.7 \%$ & 55 & 2-item MBI \\
\hline Starmer, $2015^{13}$ & CS \& L & Pediatricians & $\begin{array}{l}\text { New } \\
\text { attendings }\end{array}$ & 840 & $93 \%$ & - & $\mathrm{NV}$ \\
\hline Streu, $2014^{22}$ & $\mathrm{CS}$ & Plastic Surgeons & Attending & 505 & $71 \%$ & - & MBI-HSS \\
\hline Szender, $2016^{18}$ & $\mathrm{CS}$ & $\begin{array}{l}\text { Gynecologist } \\
\text { oncologist }\end{array}$ & Attending & 290 & $28.9 \%$ & - & NV \\
\hline $\begin{array}{l}\text { Teixeira-Polt, } \\
2017^{24}\end{array}$ & $\mathrm{CS}$ & Neurologists & Attending & 625 & $39.1 \%$ & - & $\mathrm{NV}$ \\
\hline
\end{tabular}

$\mathrm{CS}=$ cross-sectional, $\mathrm{L}=$ longitudinal, $\mathrm{QOL}=$ quality of life, $\mathrm{NV}=$ non validated, MBI-HSS = Maslach Burnout Inventory-Human Inventory Services Survey, HANDS = Harvard National Depression Screening Day Scale, QOL LASA = Quality of Life linear algorithm self-assessment, GHQ-12=12 item general health questionnaire, RDAS = Revised Dyadic Adjustment Scale, SF-8 = Optum SF-8 Health Survey, PRIME-MD = Primary Care Evaluation of Mental Disorders,

AUDIT $=$ Alcohol Use Disorders Identification Test 
Table 2. Odds Ratios

\begin{tabular}{|c|c|c|c|c|}
\hline Parameter & $\begin{array}{l}\text { Odds } \\
\text { Ratio }\end{array}$ & \multicolumn{2}{|c|}{$\begin{array}{l}\text { 95\% Confidence } \\
\text { Interval }\end{array}$} & Source \\
\hline \multicolumn{5}{|l|}{ Hours per week, burnout } \\
\hline $\begin{array}{l}\text { Working }>70 \mathrm{~h} / \text { wk positively correlated with } \\
\text { burnout }\end{array}$ & $2.50^{*}$ & 2.15 & 2.91 & de Oliveira, Change; Quershi \\
\hline $\begin{array}{l}\text { Each additional hour of work per week correlated } \\
\text { with burnout }\end{array}$ & $1.02^{*}$ & 1.01 & 1.02 & $\begin{array}{l}\text { Shanafelt, Oreskovich; Dyrbye, } \\
\text { Shanafelt; Dyrbye, West }\end{array}$ \\
\hline \multicolumn{5}{|l|}{ On call nights, burnout } \\
\hline Each additional night on call, burnout & $1.05^{*}$ & 1.03 & 1.06 & $\begin{array}{l}\text { Shanafelt, Oreskovich; Drybye, } \\
\text { Shanafelt; Drybye, Varkey }\end{array}$ \\
\hline $\begin{array}{l}\text { More than one night on call per week, emotional } \\
\text { exhaustion }\end{array}$ & $1.96^{*}$ & 1.29 & 2.97 & Streu \\
\hline More than two nights on call per week, burnout & $1.95^{*}$ & 1.58 & 2.40 & Qureshi \\
\hline 5 days or more in between nights on call, burnout & $0.62^{*}$ & 0.45 & 0.86 & de Oliveira, Chang \\
\hline \multicolumn{5}{|c|}{ Work-home conflict as related to burnout, hours, and on call nights } \\
\hline$>50$ work hours per week, satisfaction with WLB & $0.21^{*}$ & 0.13 & 0.33 & Starmer \\
\hline $\begin{array}{l}>60 \text { work hours per week, likelihood of work- } \\
\text { home conflict }\end{array}$ & $2.27^{*}$ & 2.03 & 2.54 & Dyrbye, Freischlag \\
\hline Recent work-home conflict, burnout & $2.46^{*}$ & 2.20 & 2.75 & Dyrbye, Verkey; Dyrbe, West \\
\hline $\begin{array}{l}\text { 2+ nights on call per week, likelihood of work-home } \\
\text { conflict }\end{array}$ & $1.32^{*}$ & 1.18 & 1.46 & Dyrbye, Freischlag \\
\hline \multicolumn{5}{|l|}{ Continuous vacation and burnout } \\
\hline Takes vacations & $0.86^{*}$ & 0.75 & 0.98 & Shanafelt, Oreskovich \\
\hline \multicolumn{5}{|l|}{ Knowledge of schedule, Satisfaction } \\
\hline Know schedule at least one month ahead of time & $3.60^{*}$ & 1.91 & 6.79 & Starmer \\
\hline
\end{tabular}

*Indicates statistical significance at the 0.05 level.

review that require more research. Each field of medicine has its own unique scheduling, call requirements, and patient volume that may not work with our conclusions. More studies looking at specific specialties in medicine are needed to supplement our review that included many different specialties of medicine.

While physician burnout is becoming more common in physicians at all stages of their careers, physicians-in-training are apt to have more difficult professional responsibilities and more challenging home lives since they are often starting families and thus at a different stage in their lives than older attending physicians. Seven of our reviewed articles included an average age of their physicians in their data, but only two averages were below the age of 50 , and one was below 30 . More evaluation of physician burnout during different stages of their careers could provide useful insight for administrators to better anticipate challenges physicians face over the course of a career. Last, like most literature reviews, our study was limited by our inability to quantify burnout across multiple studies. Unlike a laboratory value, identifying physician burnout is a difficult task that takes skill by the examiner and the physicians being evaluated for burnout to accurately report signs and symptoms. 


\section{Conclusions}

The following are modifiable factors within physicians' schedules that may increase satisfaction with WLB and thus decrease burnout:

1. $<70$-hour work week ${ }^{13-16}$

2. A maximum of one on-call night per five consecutive days $\mathbf{s}^{1,5,7,8,13-17}$

3. Providing physicians with schedule information a minimum of one month in advance ${ }^{10,12}$

4. Limiting the number of consecutive work days to five $^{18}$

\section{Providing allotted vacation time..$^{11}$}

We recommend creating schedules that incorporate frequent short breaks over those that emphasize infrequent but longer vacation times as a means to make these scheduling goals more realistic.

Article citation: Reinhart E, Reely K, Dowdy K, Seth N, McGrade P, Jones C, Horan MJ, Provenzano N, Ramirez P, Hammonds K, Khan S. A systematic review of burnout and its relation to work-life balance and scheduling among United States physicians. The Southwest Respiratory and Critical Care Chronicles 2020;8(34):40-46

From: Texas A\&M HSC at Baylor Scott \& White in Temple, Texas

Submitted: $2 / 23 / 2020$

Accepted: 4/17/2020

Reviewer: Drew Payne DO

Conflicts of interest: none

This work is licensed under a Creative Commons

Attribution-ShareAlike 4.0 International License.

\section{REFERENCES}

1. Dyrbye LN, Shanafelt TD, Balch CM, et al. Relationship between work-home conflicts and burnout among American surgeons. Arch Surg 2011;146(2):211-217.

2. Rabatin J, Williams E, Manwell LB, et al. Predictors and outcomes of burnout in primary care physicians. J Primary Care Community Health 2016;7(1):41-43.
3. Qureshi HA, Rawlani R, Mioton LM, et al. Burnout phenomenon in U.S. plastic surgeons: risk factors and impact on quality of life. Plastic Reconstruction Surgery. 2015;135: 619-625.

4. Holmes EG, Connolly A, Penaskovic KM, et al. Taking care of our own: a multispecialty study of resident and program director perspectives on contributors to burnout and potential interventions. Acad Psych 2017;41:159-166.

5. de Oliveira GS, Chang R, Fitzgerald PC, et al. The prevalence of burnout and depression and their association with adherence to safety and practice standards: a survey of United States anesthesiology trainees. Anesthesia Analgesia 2013; 117(1):182-193.

6. Ali NA, Wolf KM, Hammersley J, et al. Continuity of care in intensive care units a cluster-randomized trial of intensivist staffing. Am J Resp Crit Care Med 2011;184:803-808.

7. Dyrbye LN, Sotile W, Boone S, et al. A survey of U.S. physicians and their partners regarding the impact of work-home conflict. J Gen Internal Med 2013;29(1):155-161.

8. Dyrbye LN, Varkey P, Boone SL, et al. Physician satisfaction and burnout at different career stages. Mayo Clinical Proceedings 2013;88(12):1358-1367.

9. Dyrbye LN, West CP, Satele D, et al. Work/home conflict and burnout among academic internal medicine physicians. Arch Internal Med 2011;171(13):1207-1209.

10. Dyrbye LN, Freischlag J, Kaups KL, et al. Work-home conflicts have a substantial impact on career decisions that affect the adequacy of the surgical workforce. Arch Surg 2012; 147(10):933-939.

11. Guest RS, Baser R, Li Y, Scardino PT, et al. Cancer surgeons' distress and well-being, II: modifiable factors and the potential for organizational interventions. Annals Surg Oncol 2011;18(5):1236-1242.

12. Shanafelt TD, Mungo M, Schmitgen J, et al. Longitudinal study evaluating the association between physician burnout and changes in professional work effort. Mayo Clinic Proceedings 2016;91(4):422-31.

13. Starmer AJ, Frintner MP, Freed GL. Work-life balance, burnout, and satisfaction of early career pediatricians. Pediatrics 2016;137(4). doi:10.1542/peds.2015-3183.

14. Shanafelt TD, Balch CM, Bechamps G, et al. Burnout and medical errors among American surgeons. Ann Surg 2010; 251(6):995-1000.

15. Shanafelt T, Dyrbye L. Oncologist burnout: causes, consequences, and responses. J Clin Oncol 2012;30(11):1235-1241.

16. Brown SD, Goske MJ, Johnson CM. Beyond substance abuse: stress, burnout, and depression as causes of physician impairment and disruptive behavior. J Am Coll Radiol 2009;6(7):479-485.

17. Shanafelt TD, Raymond M, Horn L, et al. Oncology fellows' career plans, expectations, and well-being: do fellows 
know what they are getting into? J Clin Oncol 2014;32(27): 2991-2997.

18. Szender JB, Grzankowski KS, Eng KH, et al. Evaluation of satisfaction with work-life balance among U.S. Gynecologic Oncology fellows: A cross-sectional study. Gynecologic Oncol Reports 2016;16:17-20.

19. Robertson SL, Robinson MD, Reid A. Electronic health record effects on work-life balance and burnout within the I3 population collaborative. J Graduate Med Education 2017; 9(4):479-484.

20. Shanafelt TD, Boone $S$, Tan L, et al. Burnout and satisfaction with work-life balance among us physicians relative to the general US Population. Arch Internal Med 2012;172(18): 1377-1385.

21. Shanafelt TD, Oreskovich MR, Dyrbye LN, et al. Avoiding burnout the personal health habits and wellness practices of US surgeons. Annals Surg 2012;255(4):625-633.
22. Streu R, Hansen J, Abrahamse P, et al. Professional burnout among US plastic surgeons: results of a national survey. Annals Plastic Surg 2014;72(3):346-350.

23. Shanafelt TD, Boone SL, Dyrbye LN, et al. The medical marriage: a national survey of the spouses/partners of US physicians. Mayo Clinical Proceedings 2013;88(3):216-225.

24. Teixeira-Polt SM, Halpern MT, Keating M, et al. Factors influencing professional life satisfaction among neurologists. BMH Health Services Research 2017;17(409). doi:10.1186/ s12913-017-2343-8.

25. Sargent MC, Sotile W, Sotile MO, et al. Quality of life during Orthopaedic training and academic practice: part 2 spouses and significant others. J Bone Joint Surg 2012;4(19):22.

26. Panagioti M, Geraghty $K$, Johnson J, et al. Association between physician burnout and patient safety, professionalism, and patient satisfaction:a systematic review and meta-analysis. JAMA Intern Med 2018;178(10):1317-1330. 